E3S Web of Conferences 1, 00002 (2013)

DOI: $10.1051 / \mathrm{e} 3$ sconf/20130100002

C Owned by the authors, published by EDP Sciences, 2013

\title{
ICHMET 2012 - International Programme Committee
}

Alessandro Alimonti, Istituto Superiore di Sanità, Italy

Fabrizio Bianchi, CNR-IFC, Italy

Claude Boutron, Joseph Fourier University, France

Enrico Brugnoli, CNR-IBAF, Italy

Luigi Campanella, Sapienza University of Rome, Italy

Sergio Cinnirella, CNR-IIA, Italy

Tyler Cornelius, CNR-IIA, Italy

J. Timothy Dvonch, University of Michigan, USA

Ralf Ebinghaus, Helmholtz-Zentrum Geesthacht, Germany

Xinbin Feng, Chinese Academy of Sciences, China

Gunnar Futsaeter, UNEP, Switzerland

Philip Grandjean, University of Odense, Denmark

Ian M. Hedgecock, CNR-IIA, Italy

Milena Horvat, Institut "Jožef Stefan", Slovenia

Anna Knox, Savannah River National Laboratory, USA

Dario Marani, CNR-IRSA, Italy

Derek Muir, Environment Canada, Canada

John Munthe, IVL, Goteborg, Sweden

Jacek Namieśnik, Politechniki Gdanskiej, Poland

Stefano Nativi, CNR-IIA, Italy

Jerome Nriagu, University of Michigan, USA

Józef Pacyna, Norwegian Institute for Air Research, Norway

Michael Paller, Savannah River National Laboratory, USA

Maria Pignata, University of Cordoba, Argentian

Nicola Pirrone (Chair), CNR-IIA, Italy

Jorg Rinklebe, University of Wuppertal, Germany

William Shotyk, University of Alberta Edmonton, Canada

Ellen Silbergeld, Johns Hopkins Bloomberg School of Public Health, USA

Lesley Sloss, IEA Clean Coal Centre, UK

Luis Gonzaga Santos Sobral, CETEM, Brazil

Francesca Sprovieri, CNR-IIA, Italy

Eiliv Steinnes, NTNU, Norway

Elsie Sunderland, Harvard School of Public Health, USA

Noriyuki Suzuki, NIES, Japan

Marcello Veiga, University of British Columbia, Canada

Li Xiangdong, Polytechnic University, Hong Kong

Zueng-Sang Chen, Department of Agricultural Chemistry, Taiwan

This is an Open Access article distributed under the terms of the Creative Commons Attribution License 2.0, which permits unrestricted use, distribution, and reproduction in any medium, provided the original work is properly cited. 